\title{
Clostridium hathewayi
}

National Cancer Institute

\section{Source}

National Cancer Institute. Clostridium hathewayi. NCI Thesaurus. Code C114251.

A species of strictly anaerobic, Gram negative, rod shaped bacteria assigned to the phylum Firmicutes. This bacteria is spore forming, negative for indole, catalase, lecithinase and lipase, hydrolyzes esculin and starch, but not gelatin, does not reduce nitrate, ferments carbohydrate to produce acetate, ethanol, carbon dioxide and hydrogen, and exhibits variable motility. C. hathewayi is a part of the normal human intestinal microflora, but may also be involved in the development of acute appendicitis and bacteremia. 